\section{Is aquaculture development an effective tool for poverty alleviation? A review of theory and evidence}

James R. Stevenson ${ }^{1}$

Xavier Irz ${ }^{2}$

1 Oxfam GB

Oxfam House

John-Smith Drive

OX4 2JY Oxford

United Kingdom

<JStevenson@oxfam.org.uk>

${ }^{2}$ MTT Agrifood Research Finland

Economic Research Unit

Luutnantintie 13

00410 Helsinki

Finland

<xavier.irz@mtt.fi>

\begin{abstract}
What role does the growth in aquaculture play in poverty reduction? In theory, aquaculture development could affect the poor either positively or negatively, so the article reviews the available empirical literature. There is almost no evidence of aquaculture reducing poverty directly, but the literature presents numerous examples of how the development of aquaculture can influence poverty-related outcomes. The article concludes that the answer to the question stated in its title is highly context-specific, so rigorous social impact assessment of major projects in the sector will continue to be necessary. Further, if the objective of aquaculture development is to reduce poverty, more emphasis should be placed on the labour-intensity of new technologies, and less on their yield increasing properties. Finally, more research is needed to improve our understanding of the main barriers to adoption of aquaculture by the poor, and the effect of that adoption on the welfare of the poor.
\end{abstract}

Key words: aquaculture; developing countries; fish culture; poverty.

Subjects: animal productions; economy and rural development; fishing and aquaculture.

\section{Résumé}

L'aquaculture est-elle un outil efficace de réduction de la pauvreté ? Une revue des arguments théoriques et empiriques

Dans quelle mesure le développement aquacole peut-il contribuer à la réduction de la pauvreté ? Théoriquement, l'aquaculture peut affecter les pauvres en bien ou en mal, et l'article présente donc une revue de la littérature empirique sur le sujet. Il n'est presque jamais établi de manière directe que l'aquaculture et son développement réduisent la prévalence de la pauvreté, mais la littérature présente de nombreux exemples d'influence du développement aquacole sur le bien-être des pauvres. L'article conclue que la réponse à la question énoncée dans son titre est spécifique au contexte, ce qui justifie la réalisation d'études rigoureuses d'impact social des projets de développement aquacole. De plus, si l'objectif de ce développement est de réduire la pauvreté, il serait souhaitable de placer plus d'importance sur l'intensité en travail de nouvelles technologies et moins sur leur capacité à augmenter les rendements. Finalement, plus de recherches sont nécessaires afin de mieux comprendre les barrières à l'adoption de l'aquaculture par les pauvres et l'effet de cette adoption sur leur bien-être.

Mots clés : aquaculture ; pauvreté ; pays en développement ; pisciculture.

Thèmes : économie et développement rural ; pêche et aquaculture ; productions animales.
T he expansion of global aquaculture, often referred to as a "blue revolution", has been spectacular in the last decades. The FAO (2003) reports that production in the sector grew at an annual average rate of $7.1 \%$ in the 1980s, and 5.1\% in the 1990s, which compares favourably to almost 
any other food-producing sector. This growth, driven by important technological innovations that improved yields and facilitated the spread of aquaculture to new areas, has had important economic and social impacts. However, it remains unclear whether it has made any significant contribution to poverty reduction in developing countries, a question that we address in this article through a systematic review of existing arguments and available evidence.

This exercise is justified because for many governments and donors, supporting aquaculture is not a goal in itself but a means of delivering societal outcomes. For instance, the UK Government Department for International Development (DFID)'s Aquaculture and Fish Genetics Research Programme (AFGRP) no longer focuses exclusively on the generation of new knowledge, but also on the promotion of the use of that knowledge to improve the livelihoods of poor people. In turn, this approach is justified by the UK's commitment to achieving the Millennium Development Goals, the bestknown component of which is a target for reduction of absolute poverty. Hence, it is crucial for policy-makers and related stakeholders, including research institutions, to establish whether aquaculture development represents an effective tool for poverty reduction. Yet, we are not aware of any other comprehensive review of the literature tackling this issue.

Academic work to date on the social impact of new agricultural technology in general, and the Green Revolution in particular, suggests that we are unlikely to find a single answer to the question of whether aquaculture development reduces poverty. Technology itself does not have any inherent pro-poor or antipoor causal property, and whether the Green/Blue Revolution or any other technology enhances or mitigates poverty is contingent on the institutional, political, economic, social, and natural environments in which development takes place (Das, 2002). The relation between aquaculture and poverty is therefore an empirical question, which we investigate in this review by assessing the pathways, constraints, and environments in which aquaculture impacts on poverty alleviation.

Our review starts in the next section with a brief conceptual analysis of the issue that demonstrates its complexity and identifies potential impact pathways. We then review the empirical evidence of the direct impact of aquaculture development on the welfare of the poor. This evidence is however extremely limited, which forces us to investigate the issue more indirectly by analysing the significance of positive and negative outcomes that represent driving forces in the impact pathways.

\section{Conceptual framework}

When aquaculture develops in a region or country there are only a few necessary outcomes: people decide to enter the sector; land is converted to ponds or space in lakes and rivers is acquired; other factors of production are used; fish are produced. Whether these outcomes ultimately have a positive or negative impact on poverty is contingent on the context. Further "contingent outcomes" may or may not occur, may be strong or weak, and may have a positive or a negative impact on the extent and/or depth of poverty. This conceptual framework for reviewing the evidence linking aquaculture development and poverty is outlined in figure 1 , which identifies all the poverty-related outcomes that we analyse in detail in this review.

\section{Empirical evidence of the direct impact on the welfare of the poor}

Ideally, the impact of aquaculture development on the poor would be investigated by measuring robust poverty indicators to allow comparison of the existing situation with a counterfactual ${ }^{1}$ built from convincing data to establish causality/ attribution. In practice, however, few studies have analysed rural aquaculture's contribution to household income (Charles et al., 1997). Irz et al. (2007) represents the only relevant piece of research that we found in the course of the review. Using data from households

\footnotetext{
${ }^{1}$ This refers to the situation that would prevail in the absence of aquaculture, or of its most recent development.
}

randomly sampled in five case-study communities in the Philippines, those authors conclude that the poor disproportionately benefit from aquaculture development, based on a mix of quantitative and qualitative analysis. In particular, a Gini-decomposition exercise demonstrates that aquaculture in the selected communities is an inequality-reducing source of income. The data also reveals that while the non-poor benefit more from aquaculture in absolute terms, the poor derive a relatively larger share of their income from aquaculture than the non-poor, i.e., they benefit a lot more in relative terms: an average of $44 \%$ of their income, compared with $23 \%$ for the nonpoor. However, a realistic counterfactual in this case was difficult to establish - aquaculture has been practiced in the Philippines in some form for a long time, so that establishing what some of the communities would be like in the absence of aquaculture cannot be determined with any confidence. In mitigation of this fact, the authors attempted to sample from communities that had varying degrees of land coverage with aquaculture. Concerns remain regarding causality in this particular study and a lack of timeseries data makes it impossible to address them rigorously.

Given the difficulty of establishing a direct link between aquaculture development and poverty reduction, we now turn to the analysis of the contingent outcomes in the impact pathways identified in figure 1 .

\section{Analysis of the positive outcomes \\ Entry into aquaculture by the poor}

Direct entry into the sector by the poor is the most obvious manner in which aquaculture can alleviate poverty. The relatively high value of most aquatic products means that entry into the aquaculture sector is likely to yield a high rate of return on resources invested (land, family labour, and capital). It follows intuitively that, were the poor able to gain access to the necessary factors of production, the 


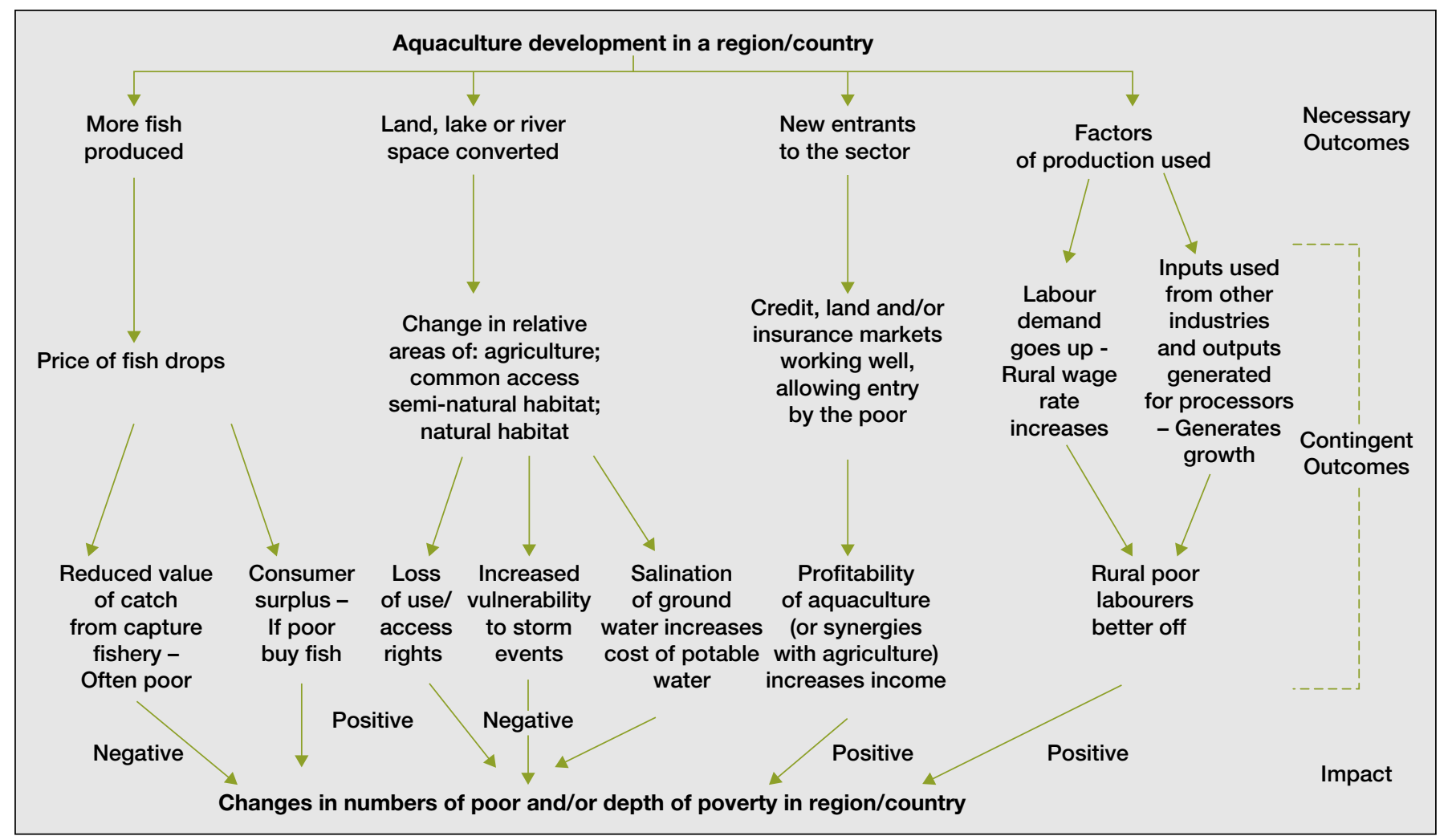

Figure 1. Impact pathways.

Figure 1. Représentation schématique des effets de l'aquaculture sur la pauvreté.

potential for poverty alleviation would be enormous.

However, there are a number of constraints to entry into the aquaculture sector related to market imperfections that are persistent across less developed countries (LDCs). For instance, the robust "inverse relationship" between farm size and productivity that is usually observed in LDCs indicates that various constraints prevent the allocation of land to the most efficient farms (Bardhan, 1973; Berry and Cline, 1979; Barrett, 1996; Heltberg, 1998). It has also been shown that the market for land, as a rule, is extraordinarily thin (Bardhan and Udry, 1999), which also suggests that it does not allocate this factor of production where it would yield the highest returns in the agrarian economy. The market failure can easily be explained if land holds a non-productive (e.g., collateral, prestige) value to its owner (Bardhan and Udry, 1999). Credit is also a production factor to which the poor might not have access due to market failure caused primarily by informational asymmetries between lenders and borrowers. The implication is that the poor may not be able to purchase essential inputs into the production process for aquaculture products (e.g., seedlings, feeds, or even land).

Uninsured risk is another major factor that prevents new entrants from engaging in profitable activities. This seems particularly relevant for many types of aquaculture, owing to the fragility of the crop, as well as the multiple environmental stresses and limited control that can be exerted by the owner when a production system is only semi-closed. Finally, the general level of familiarity with, and knowledge of, aquaculture among the population is also central to the ability of the poor to adopt aquaculture as a way of evading poverty.

The case studies reported in the literature suggest that access to credit does constrain entry into aquaculture. Informal institutions of credit provision lying outside the banking sector tend to dominate, as illustrated by the Bangladeshi system of Dadon credit system described by Ito (2004). Owners of local depots, where prawn harvests are graded and the first sale takes place, offer advances to aqua- culture producers on the condition that they supply their harvests to the agent. This leaves the producers open to abuse by the depot owners at harvest time, as the depot owners "tend to underrate the size of prawns in order to buy them at prices below the market rates" (Ito, 2004, p.1009). In a similar vein, Agbayani et al. (1997) report on a number of sources from different countries across Asia that suggest that the same story applies: "middlemen and wholesalers lend money to cash-strapped fish farmers and fry gatherers and then pressurise them to sell their products at a much lower price than the fair market price". While those practices at least ensure that some form of credit is available to potential operators, they clearly concentrate the gains from aquaculture and create a disincentive for the poor to enter the sector. However, the literature also reports cases where informal institutions providing credit to aquaculture function more equitably. Hence, Stevenson (2006) gives a detailed analysis of credit provision to brackish-water fish farms by buying stations (consignations) in the Philippines to 
conclude that incentives built into the system prevent the kind of exploitation seen in Bangladesh.

The literature also provides some clues into the imperfect functioning of the land market in LDCs as it relates to aquaculture. Stevenson (2003) reports that the degree of land concentration for the two main regions of brackish-water aquaculture of the Philippines is very high, as evidenced by a Gini coefficient of 0.72 . This indicates that the current level of land concentration in brackish-water aquaculture compares to that observed for agricultural land in the whole country prior to the Comprehensive Agrarian Reform Law (CARL). This is an unsurprising finding given that brackish-water areas have been exempted from the CARL, but it is difficult to believe that the allocation of vast areas of brackish-water land to absentee owners in regions stricken by absolute poverty is efficient. More indirectly, one can observe that aquaculture development in Asia has been most spectacular in three countries that have carried out successful agrarian reforms, namely Taiwan, China, and Vietnam. The positive impact of the reforms on poverty in the three countries has been analysed in depth by Griffin et al. (2002) without particular reference to aquaculture, but it seems almost certain that the sector has played a significant role in alleviating poverty among those smallholders able to adopt fish farming.

The literature also reports case studies that demonstrate that access to land by the poor for aquaculture can be a problem, although the situation varies even within countries. For instance, Ito (2004) establishes that in Bangladesh, coastal lands under brackish-water aquaculture, although legally owned by the government, are susceptible to concentration by powerful business people. This contrasts with the situation for inland agricultural plots, which have clearly defined private ownership, and thus are less susceptible to being concentrated among a few hands. Land leases on privately owned plots are available at low rates in less favourable areas, unsuitable for either rice farming or brackish-water aquaculture, but that offer the possibility of conversion into a simple pond for freshwater prawn farming. In that context, access to credit, rather than access to land per se, seems to be the binding constraint that prevents the poor from taking advantage of the opportunities offered by inland aquaculture (Ito, 2004).
With respect to the skills barrier, the level of knowledge of aquaculture among the rural poor is related to the depth of the tradition in a particular country or region, as well as the size and efficiency of the government extension service. It suggests that several countries in Asia with long traditions of aquaculture (e.g., China, India, Indonesia, Philippines) have an ingrained advantage in tapping into its potential for poverty reduction over most African countries, among which only Egypt has a significant tradition of fish culture.

\section{Employment on aquaculture farms by the poor}

The long-term potential for poverty alleviation from aquaculture development is through the sustained creation of a large number of these low-skilled jobs that are accessible to the poor, and that ultimately serve to drive up the rural wage rate. It is estimated that the global shrimp farming industry alone generates employment for around 2 million people (Singh, 1999). As an example of how employment on shrimp farms can benefit the poor, Singh also reports that the lowest grade of employee on shrimp farms in Mexico earned an average of 1.22 times the average annual income in 1996. Similarly, de Farias Costa and Sampaio (2004) find that shrimp farms in Brazil directly generate 1.89 jobs per hectare. This figure represents a greater labour demand than alternative land uses (such as irrigated fruit production, sugar and coconut production) in the Northeast coastal region in Brazil. In Honduras, Stanley (2003) estimates that shrimp mariculture directly generates 100-150 person days per hectare per year. The above case studies strongly suggest that aquaculture is more labour intensive than alternative land uses and thereby contributes to raising rural wage rates and the living standards of the poor.

However, the reality is probably more complex, as illustrated by the socioeconomic analysis of Philippine brackish-water aquaculture of Stevenson (2006). The study established that, even locally in the coastal areas of the Philippines, labour intensity of aquaculture production varies substantially across farm types. For instance, mean demand for hired labour on low-input systems was estimated to be as much as 211.5 per- son days per hectare per year, which is almost four-fold the labour requirement on large, milkfish-oriented farms. Hence, the ability of aquaculture to generate employment for wage labourers varies significantly with the technology adopted on farms.

\section{Employment in associated upstream and downstream industries by the poor}

Industries linked to aquaculture (for supplying inputs, processing outputs and marketing) provide a source of employment for the poor, depending on the labour demand of these industries and the extent to which the aquaculture sector is integrated into the local economy (Stanley, 2003). The output from aquaculture is highly perishable, and consequently there is a limit to the extent to which processing and marketing industries can be concentrated, thus ensuring a certain level of labour demand. Furthermore, these downstream activities of processing (cleaning, sorting, descaling, filleting, etc) and marketing are likely to have a positive gender bias in favour of women in most countries (see Siar and Caneba (1998) for an example in the Philippines). The empirical evidence of the significance of those employment linkages within regional economies is, however, mixed. de Farias Costa and Sampaio (2004) find that the shrimp industry in Brazil indirectly generates 1.86 jobs per hectare of farm, which almost matches the on-farm employment generation reported in the previous section. By contrast, Stanley (2003) finds only 0.25 FTE (fully-time equivalents) per hectare generated indirectly from shrimp aquaculture in Honduras. The author further concludes that, of the potential wider benefits to the local economy of the industry, only employment spill-overs (i.e., the skills learnt by workers in aquaculture which are transferable to other sectors) are positive. All other aspects (primary and secondary economic linkages, fiscal and consumption linkages and investment spill-overs) are either negligible or negative in their effect. In another context, Stevenson (2006) reports that the demand for labour generated by aquaculture off-farm is relatively small in the coastal areas of the Philippines: the preparation of inputs used by aquaculture accounts for only $11 \%$ of the total labour demand (260 person days per hectare per year); and the 
corresponding proportion for the processing of aquaculture products is only $10 \%$. Several studies also demonstrate that while aquaculture often has the potential to generate a lot of employment regionally, this potential is probably rarely realised because of necessary trade-offs among developmental objectives. Hence, El-Gayar and Leung (2001) analyse aquaculture development in Northern Egypt in a multi-criteria decision-making model with three objectives: employment, supply of fish, and foreign exchange earnings. The model estimates that adopting a strategy to maximise employment from aquaculture would create over 5000 jobs. By contrast, if either regional availability of fish or foreign exchange earnings were maximised, then job creation would fall to 3,500 or 1,200 respectively. Martinez-Cordero and Leung (2004) also find trade-offs between employment and other objectives in aquaculture development in Northwest Mexico, albeit of lesser significance than in the previous study of Egypt.

\section{Increased supply of fish for consumption by the poor}

Increased fish supply for consumption by the poor is an often-cited rationale for promoting aquaculture in LDCs (Edwards, 2000; Ahmed and Lorica, 2002).

The expected direct effect of an increase in supply of fish is a decrease in the price for protein in local markets. In addition to the direct decrease in price of the farmed fish, substitutions in consumption imply that the price of other sources of protein (e.g. beans; small, wild-caught fish) is also expected to decline. Those combined price effects should benefit the poor disproportionately as the poor spend a greater percentage of their income on food. Indirect, more long-term positive nutritional and health effects of an increase in protein intake by the poor are also expected but difficult to attribute to aquaculture, given the complexity and timescales associated with these causal links.

The reality may be more complex than suggested by the above argument, because "fish" is not a homogenous commodity: there are different classes of products from alternative sources and different classes of consumers. However, demand for fish can be analysed econometrically at a disaggregated level, as has been done by Dey (2000) and Garcia et al. (2005) for Bangladesh and the Philippines respectively. Both papers establish that the demand for fish is elastic and, more directly relevant to our investigation, Garcia et al. (2005) find that there is considerable price responsiveness of demand for tilapia and milkfish (the two main domestically consumed aquaculture species in the Philippines) from lower income groups. This supports the idea that a reduction in the price of farmed fish achieved through further aquaculture development improves the welfare of the poor.

\section{Poor farmers integrating aquaculture into small agricultural farms}

The rationale for considering the integration of agriculture into small agricultural farms separately from outright adoption is that integration might produce synergistic effects that increase the overall efficiency of the farming system. The presence of a pond on a small farm may therefore provide secondary benefits to the farmer (e.g. through nutrient cycling, water storage for irrigation, etc.) in addition to the income gained from the pond directly, which together can significantly raise farm incomes. There is also the potential for fish culture in rice paddies during wet season floods (Berg 2002; Dey et al., 2005).

However, there has been a lack of empirical evidence to support the claims made on behalf of integrated aquacultureagriculture: the agenda, it seems, has been supported somewhat uncritically by ICLARM / WorldFish Center in particular, as a means to enhancing smallholder incomes and ensuring efficient use of natural resources by effective nutrient cycling. The paper by Prein et al. (1998) is the exception to this rule, as the authors provide evidence from three case-study countries - Ghana, Malawi and the Philippines - to demonstrate the tangible benefits of integration. In Ghana, Prein et al. (1998) find that families increased their protein intake from $60 \%$ of recommended levels, to $120 \%$, following integration of aquaculture on their farms. In Malawi, households were able to stabilise or slightly increase their supply of food and cash crops in a year (1992) of drought and a currency devaluation of $20 \%$. In the Philippines case study, the authors compared farm-level performance before and after integration of aquaculture into the farming system against four sustainability indicators: net income, resource system capacity, species diversity, and bioresource cycling. All four indicators showed significant increases following the adoption of aquaculture by farmers, suggesting that integration increases sustainability and that there are no trade-offs among ecological and economic objectives in this case, although there is no measure of whether the farms under study were those of poor families. More generally, the literature provides little evidence on the barriers to adoption of aquaculture by poor farmers in LDCs, with most studies in aquaculture economics focusing on the adoption of particular technologies by existing aquaculturists (e.g. Sevilleja, 2002; Rauniyar, 1998). The significance of this gap in the literature is highlighted by Ahmed and Lorica (2002, p. 138): "At the current level of adoption income effects are still modest, but, given the high profitability, the potential for much higher impacts on household income does exist, suggesting that it is crucial to understand the constraints to more intensive adoption by the farm households".

\section{Negative outcomes}

\section{Conversion or privatisation of land for aquaculture}

Particularly in coastal areas, aquaculture development can exclude the poor and lead to a loss of customary or informal access rights to a harvestable resource (e.g. mangroves). From a mainstream economics standpoint, the Kaldor-Hicks criterion (Hicks, 1939) that underpins costbenefit analysis identifies potential Pareto improvements where the gainers could potentially compensate the losers. The controversy with regard to the development of public lands for aquaculture comes from the fact that mechanisms through which this compensation can be made are rarely put in place, and so this narrow view of economic efficiency comes up against distributional issues.

This debate has been particularly intense with reference to the conversion of ecologically important mangrove areas into fishponds, but here again the empirical evidence of the significance of the phenomenon is mixed. For instance, 
Alonso-Perez et al. (2003), using satellite image data from 1984 and 1999, establish that in the Ceuta coastal lagoon of Sinaloa, Mexico, the growth in shrimp aquaculture has only had a marginal impact on mangroves as ponds are typically sited on areas of bare substratum and saltmarsh. On the other hand, Adger and Luttrell (2000) present a convincing case that property rights regimes in relation to wetlands have important implications for the distribution of benefits of use among users and non-users. Based on two case studies in Indonesia and Vietnam, they argue that state appropriation of wetland resources or the imposition of private property rights can contribute to their unsustainable utilisation. Abstracting from distributional issues, some authors question whether aquaculture based on private ownership of previously commonly held resources represents an efficient use of those resources. Hence, in an ex-ante appraisal, Nickerson (1999) assesses alternative strategies for managing the small area of mangrove in the Gulf of Lingayen, Philippines, that has not been converted to aquaculture. The author models population dynamics in mangrove-dependent fish and the distribution of benefits among alternative stakeholders under three scenarios for the mangrove: left undeveloped, developed for polyculture, and developed for semiintensive shrimp culture. The results favour the undeveloped option that yields higher overall monetary benefits than either forms of aquaculture, and supports a more equitable distribution of those benefits.

\section{Environmental burdens falling disproportionately on the poor}

Aquaculture can have several potential negative impacts on capture fisheries and, consequently, affect the livelihoods of poor artisanal fishermen adversely (Barbier, 2000). Naylor et al. (2000) stress the following impact mechanisms:

- habitat modification - Mangrove loss means that near-shore fish stocks have fewer nursery areas, both directly (mangrove) and indirectly (mangrove loss impacts on coral reefs and seagrass bed deterioration);

- use of wild seed to stock aquaculture ponds;

- food web interactions - Overexploitation of small pelagics for fishmeal, although aquaculture is not the only destination for fishmeal;

- introduction of non-indigenous organisms - Hydridisation of farmed stocks with wild, causing genetic pollution through loss of adaptive traits;

- effluent discharge - Nutrient pollution can cause problems in coastal areas.

Those impacts may be compounded by a limited range of alternative sources of livelihood in resource-dependent communities (Bailey and Pomeroy, 1996). Some even suggest that the end result is the temporary, cyclical or permanent migration in search of gainful employment from fishing communities (Allison and Ellis, 2001). Linking the potential ecological impacts on fisheries to the livelihoods of poor fishermen has, however, not been established convincingly in the literature. A number of studies have reported extremely high by-catch for wild-caught seed, particularly for shrimp (Banerjee and Singh, 1993; Frankenberger, 2002; Islam and Haque, 2005), although how these translate into losses to capture fisheries is very difficult to establish owing to the multiple sources of mortality for fish and shrimp early in their life-cycle. Food web interactions, and the introduction of non-indigenous organisms are both long-term stressors on wild fisheries stocks, but it is very difficult to estimate their contribution to declines in fish stocks and subsequent impacts on the livelihoods of poor fishermen. Despite these difficulties in establishing causality, a sympathetic attitude towards capture fishermen pervades much of the literature owing to the perceived inequality (economic, social, political) between aquaculture operators and captures fishermen. This seeking of redress is entirely justifiable, but poverty impacts are not documented.

At another level, there is growing interest in the potential increases in vulnerability of coastal communities through a reduction in resilience to storm surges, tidal waves and tsunamis that result from mangrove deforestation (Adger and Luttrell, 2000; Barbier, 2006). This loss of resilience is felt most strongly by the poor, whose housing is likely to be in the more dangerous areas, and built with the most basic materials.

Although the negative externalities generated by inland pond aquaculture seem relatively less important, there is evidence of adverse impacts on the poor in that context as well. An example here is the case of groundwater or fields becoming saline as a result of aquaculture (Dierberg and Kiattisimkul, 1996). This can potentially hamper agricultural production (e.g., rice farming) and raise the effective cost of drinking water, which is felt more keenly by poor families. There is evidence that the problem is significant, at least locally. Hence, sixty-five per cent of villages studied by Patil and Krishnan (1997) in Andra Pradesh reported having been affected by the problem of drinkingwater salinity attributed to shrimp farming. Be et al. (1999) also show that salinization of rice-shrimp fields and neighbouring rice monoculture fields, and the build-up of sediment in rice-shrimp fields, imposes large external costs on rural households of the Mekong Delta.

\section{Reduced market price for fish reduces income for poor fishermen}

A potential reduction in the incomes of poor fishermen as a result of aquaculture development is the opposite side of the argument made previously about the benefits to poor consumers of a drop in the price of fish on the market. In countries where capture fisheries are a particularly important source of livelihood for poor people, and where the majority of consumers of fish are either concentrated in urban areas and are not poor, then a price drop in fisheries products through aquaculture development may have an overall negative impact on the poor. However, this does not need to be the case if wild and farmed fish are sold on largely separate markets. This hypothesis is investigated econometrically by Garcia et al. (2005) who analysed demand for fish at a disaggregated level in the Philippines. The authors find very low crossprice elasticities of demand for farmed species on the one side (tilapia, milkfish and shrimp), and wild-caught fish on the other. This suggests that, as aquaculture develops and the price of farmed fish decreases, the decline in the price of wild-caught fish is minimal, and the adverse impact on poor fishermen is therefore limited.

\section{Conclusion}

While the evidence regarding the ability of aquaculture development to reduce 
poverty is incomplete, this review supports a number of general observations and policy recommendations. The first one, unsurprisingly, is that there is no single answer to the question set out in the title of this article, because the relations of the poor to aquaculture vary enormously even within small regions of particular countries. Hence, if an aquaculture development project is proposed with the sole aim of improving the welfare of the poor, an extensive assessment of its impacts should consider the multiple ways in which it can affect poverty.

The second conclusion relates to the fact that, as stated by Ahmed and Lorica (2002), while there is "clear evidence of positive income and consumption effects of aquaculture on households [...] employment effects are still not significant." Given that increasingly the poor are labourers rather than small farmers (Das, 2002), at least in Asia, the employment impacts of aquaculture are crucial to determining its overall impact on poverty. A much greater focus on this aspect of aquaculture, both in applied research and development (i.e. in promoting labour-intensive aquaculture technologies) and in impact assessment research (i.e. considering aquaculture in a broad livelihood context), would be desirable. By contrast, the traditional emphasis on the yield-increasing potential of new technologies does not seem entirely warranted if the primary aim is to reduce poverty.

The review also highlights the fact that, in situations where poor farmers could adopt aquaculture, either as a sole activity or integrated with other agricultural productions, the barriers to that adoption remain poorly understood. While it is clear that failures of the credit, land, and insurance markets play a role, the decisions to enter or exit the sector should be investigated further in relation to poverty in a dynamic framework. For instance, the fact that very few fish farmers are poor at a given time could indicate that only the relatively well off partake in that activity. However, it could also be the case that aquaculture offers an effective mechanism out of poverty for those able to enter the sector.

Finally, the review shows that the negative impacts of aquaculture development on the poor are more relevant with reference to coastal aquaculture, and relate primarily to its environmental impacts both in the initial change in land-use (in the case of pond construction), and from on-going impacts that occur during operation (salination and reduced resilience especially). Literature on the initial change in land rights provides the most convincing evidence of negative poverty impacts from aquaculture, and this suggests two things. Firstly, where aquaculture is established (i.e. where the change in land-rights has already taken place), it is imperative that it is to be made sustainable. Changes from natural ecosystem to aquaculture ponds can be considered virtually irreversible and so abandonment would leave land unproductive. Secondly, new proposed changes in landrights to allow privatisation for aquaculture development should be subjected to rigorous social impact assessments to establish whether poor people are to be significantly impacted through loss of land-use rights.

\section{References}

Adger WN, Luttrell C. Property rights and the utilisation of wetlands. Ecol Econ 2000; 35: 75-89.

Agbayani RF, Belleza ET, Agbayani EC, et al. Aquaculture economics in Asia and the Pacific: a regional assessment. FAO Fisheries Circular (FAO). 0429-9329, n 932. Rome: FAO, 1997.

Ahmed M, Lorica MH. Improving developing country food security through aquaculture development - Lessons from Asia. Food Policy 2002; 27: 125-41.

Allison EH, Ellis F. The livelihoods approach and management of small-scale fisheries. Mar Policy 2001; 25: 377-88.

Alonso-Perez F, Ruiz-Luna A, Turner J, Berlanga-Robles' CA, Mitchelson-Jacob G. Land cover changes and impact of shrimp aquaculture on the landscape in the Ceuta coastal lagoon system, Sinaloa, Mexico. Ocean Coast Manage 2003; 46: 583-600.

Bailey C, Pomeroy C. Resource dependency and development options in coastal Southeast Asia. Soc Nat Resour 1996; 9: 191-9.

Banerjee BK, Singh $\mathrm{H}$. The shrimp bycatch in West Bengal. Madras (India): Bay of Bengal Programme, 1993.

Barbier EB. Valuing the environment as input: review of applications to mangrove-fishery linkages. Ecol Econ 2000; 35: 47-61.

Barbier EB. Natural barriers to natural disasters: replanting mangroves after the Tsunami. Frontiers Ecol Environ 2006; 4: 124-31.

Bardhan PK. Size, productivity and returns to scale: an analysis of farm-level data in Indian agriculture. J Polit Econ 1973; 81: 1370-86.

Bardhan P, Udry C. Development Microeconomics. Oxford (UK): Oxford University Press, 1999.

Barrett $\mathrm{CB}$. On price risk and the inverse farm size-productivity relationship. J Dev Econ 1996; 51: 193-216.
Be TT, Dung LC, Brennan D. Environmental costs of shrimp culture in the rice-growing regions of the Mekong Delta. Aquac Econ Manag 1999; 3: 31-42.

Berg $\mathrm{H}$. Rice monoculture and integrated ricefish farming in the Mekong Delta, Vietnam Economic and ecological considerations. Ecol Econ 2002; 41: 95-107.

Berry RA, Cline WR. Agrarian structure and productivity in developing countries. Baltimore: John Hopkins University Press, 1979.

Charles AT, Agbayani RF, Agbayani CE, et al. Aquaculture economics in developing countries: regional assessments and an annotated bibliography. Rome: FAO, 1997 (FAO Fisheries Circular, $n^{\circ}$ 932).

Das RJ. The green revolution and poverty: a theoretical and empirical examination of the relation between technology and society. Geoforum 2002; 33: 55-72.

Dey MM. Analysis of demand for fish in Bangladesh. Aquac Econ Manag 2000; 4: 65-83.

Dey MM, Briones RM, Ahmed M. Disaggregated analysis of fish supply, demand, and trade in Asia: baseline model and estimation strategy. Aquac Econ Manag 2005; 9: 113-39.

Dierberg FE, Kiattisimkul W. Issues, impacts and implications of shrimp aquaculture in Thailand. Environ Manag 1996; 20: 649-66.

Edwards P. Aquaculture, poverty impacts and livelihoods. Natural Resource Persectives, 56. London: Overseas Development Institute, 2000.

El-Gayar OF, Leung P. A multiple criteria decision-making framework for regional aquaculture development. Eur J Oper Res 2001; 133: 462-82.

de Farias Costa E, Sampaio Y. Direct and indirect job generation in the farmed shrimp supply chain. Aquac Econ Manag 2004; 8: 143-56.

FAO. The State of the World Fisheries and Aquaculture 2002. Rome: FAO, 2003.

Frankenberger TR. A livelihood analysis of shrimp fry collectors in Bangladesh: future prospects in relation to a wild fry collection ban. Dhaka (Bangladesh): DFID, 2002.

Garcia YT, Dey MM, Navarez SMM. Demand for fish in the Philippines: a disaggregated analysis. Aquac Econ Manag 2005; 9: 141-68.

Griffin K, Khan AR, Ickowitz A. Poverty and the distribution of land. J Agrarian Change 2002; 2: 279-330

Heltberg R. Rural market imperfections and the farm size-productivity relationship: evidence from Pakistan. World Dev 1998; 26: 1807-26.

Hicks JR. The foundations of welfare econom ics. Econ J 1939; 49: 696-712.

Ito S. Globalization and agrarian change: a case of freshwater prawn farming in Bangladesh. J Int Dev 2004; 16: 1003-13.

Islam MS, Haque M. The mangrove-based coastal and nearshore fisheries of Bangladesh: ecology, exploitation and management. Rev Fish Biol Fish 2005; 14: 153-80.

Irz XT Stevenson JR, Villarante $P$, Tanoy $A$ Morrisens $P$. The equity and poverty impacts of aquaculture: insights from the Philippines. Dev Policy Rev 2007; 25: 495-516.

Martinez-Cordero FJ, Leung PS. Multicriteria decision-making (MCDM) model for regional sustainable shrimp farming development in northwest Mexico. Aquac Econ Manag 2004; 8 : 175-88. 
Naylor RL, Goldburg RJ, Primavera JH, et al. Effect of aquaculture on world fish supplies. Nature 2000; 405: 1017-24.

Nickerson D. Trade-offs of mangrove area development in the Philippines. Ecol Econ 1999; 28: 279-98.

Patil PG, Krishnan M. The Kanderleru shrimp farming industry and its impacts on the rural economy: an empirical analysis. Agric Econ Res Rev 1997; 10: 293-308.

Prein M, Lightfoot C, Pullin RSV. ICLARM's approach to the integration of aquaculture into sustainable farming systems. In: Aquaculture sustainability and environment - Report on a regional study and workshop on aquaculture sustainability and environment. Bangkok: ADB/NACA, 1998.
Rauniyar GP. Adoption of management and technological practices by fishpond operators in Nepal. Aquac Econ Manag 1998; 2: 89-100.

Sevilleja RC. Adoption and economics of tilapia farming technology in the Philippines. Paper presentation at the International Institute of Fisheries Economics and Trade (IIFET) Conference: Fisheries in the Global Economy August 19-22 2002, Wellington, New Zealand, 2002.

Siar SV, Caneba LM. Women and the question of sustainable development in a Philippine fishing village. Int J Sustainable Dev World Ecol 1998; 5: 51-8.

Singh T. Benefits of sustainable shrimp aquaculture. INFOFISH Int 1999; 3/99: 25-32.
Stanley DL. The economic impact of mariculture on a small regional economy. World Dev 2003; 31: 191-210.

Stevenson JR. Sustainability of brackish-water pond aquaculture systems: a farm-level analysis of economic, social and ecological dimensions in the Philippines. PhD Thesis, Department of Agricultural and Food Economics, University of Reading, UK, 2006.

Stevenson JR, Irz XT, Primavera JH, Sepulveda G. Coastal aquaculture systems in the Philippines: social equity, property rights and disregarded duties. Proceedings of a Multidisciplinary Scientific Conference on Rights and Duties in the Coastal Zone, Royal Swedish Academy of Sciences, 12-14 June 2003. 